\title{
A traditional Chinese medicine formulation consisting of Rhizoma Corydalis and Rhizoma Curcumae exerts synergistic anti-tumor activity
}

\author{
JIAN-LI GAO ${ }^{1}$, TONG-CHUAN HE ${ }^{2}$, YING-BO LI ${ }^{1}$ and YI-TAO WANG ${ }^{1}$ \\ ${ }^{1}$ Institute of Chinese Medical Sciences, University of Macau, Macau 999078, P.R. China; ${ }^{2}$ Molecular Oncology \\ Laboratory, Department of Surgery, The University of Chicago Medical Center, Chicago, IL 60637, USA
}

Received June 2, 2009; Accepted July 14, 2009

DOI: 10.3892/or_00000539

\begin{abstract}
Synergy analysis of anticancer agents is an important approach to determining the ratio and/or dose of drugs for clinical combination therapy. However, this method is rarely used to evaluate the composition of traditional Chinese medicine formulation. 'Yanhusuo San' (YHSS), which consists of yanhusuo (Rhizoma Corydalis) and Ezhu (Rhizoma Curcumae), has been an archaic Chinese medicine prescription since the Song dynasty (960-1279 AD). We previously demonstrated that either yanhusuo or ezhu has strong anticancer effect. Herein, we sought to determine the possible synergic effect between these two Chinese herbs. We measured the $\mathrm{IC}_{50}$ of each herb extract and both extracts at different ratios of doses by MTT assay. Isobologram and combination index (CI) analyses were used to evaluate the synergistic effect of yanhusuo and ezhu in different fixed ratios. Our results indicated that a combination of two herbal extracts exhibits the strongest anticancer cell proliferation effect at the ratio of 3:2 (ezhu to yanhusuo; referred to as E3Y2). Using Boyden Chamber assay, flow cytometry, and fluorescence microscopy analysis, we found that E3Y2 could markedly reduce the cell invasion ability and induce cytochrome $\mathrm{c}$ release rather than single use, but E3Y2 could not influence the cell cycle distribution. When the levels of ERK1/2, p-ERK1/2 and $\mathrm{p}-\mathrm{Rb}$ were determined by Western blot analysis, we found that the E3Y2 significantly suppresses the level of p-ERK. Thus, our studies provide a plausible molecular basis of the synergistic anti-tumor effect of ezhu and yanhusuo.
\end{abstract}

Correspondence to: Professor Y.-T. Wang, Institute of Chinese Medical Sciences, University of Macau, Av. Padre Tomás Pereira S.J., Taipa, Macao 999078, P.R. China

E-mail: ytwang@umac.mo

Dr T.-C. He, Molecular Oncology Laboratory, Department of Surgery, The University of Chicago Medical Center, 5841 South Maryland Avenue, MC 3079, Chicago, IL 60637, USA

E-mail: tche@surgery.bsd.uchicago.edu

Key words: combination effect, synergy, Yanhusuo San

\section{Introduction}

Combination therapy with multiple drugs is a common practice for cancer treatment because combining two or more types of anticancer agents may be more effective than a single one alone (1). The potentially favorable outcomes for synergism include: 1) increasing the efficacy of the therapeutic effect, 2) decreasing the dosage of the drugs but increasing or maintaining the same efficacy to avoid toxicity, 3) minimizing or slowing down the development of drug resistance, and 4) providing selective synergism against cancer target (or efficacy synergism) versus host (or toxicity antagonism) (2). Thus, evaluation of drug-drug interaction is important in cancer chemotherapy. The quantitative assessment of drug combinations is necessary to the judgment of synergy in several areas, such as the combination therapy in the epilepsy, antiHIV-1 infection, malaria, antibiotic therapy and cancer chemotherapy (3-7). Isobologram and combination index (CI) analyses are the two most popular methods for evaluating drug interactions (8). However, these methods were less frequently used in the quantity evaluating of combination effect in other areas, such as ethnological medicine $(9,10)$.

Prescription (mixture formulation of herbal drugs, usually called 'fufang' in Chinese) is the most important character of Traditional Chinese Medicine (TCM). Successful use of 'fufang' in TCM makes it necessary to find a rationale for the pharmacological and therapeutic superiority of many of them in comparison to isolated single constituents. There is a lack of suitable methods to evaluate the features and quantitative extent of drug interaction in TCM although various approaches have been reported to assess potential synergism and antagonism in cancer treatment. Herein, we evaluated the drug interaction and investigated the molecular basis of the potential synergism exhibited by a commonly-used TCM prescription, namely 'Yanhusuo San' (YHSS).

YHSS consists of Yanhusuo (Rhizoma Corydalis) and Ezhu (Rhizoma Curcumae) and has been an archaic Chinese medicine prescription since Song Dynasty (960-1279 AD). YHSS was first recorded in 'Ji Feng Pu Ji Fang (vol. 20)' and 'Zhu Shi Ji Yan Fang (vol. 10)' in the Song dynasty, and used to improve blood circulation, to remove blood stasis, and to promote circulation for pain relief in women. In our previous studies (11-13), we found that both yanhusuo and ezhu could 
inhibit cancer cell proliferation, and that ezhu could induce cancer cell apoptosis, whereas yanhusuo was shown to inhibit metastasis.

In order to determine the effects of drug-drug interaction between yanhusuo and ezhu, isobologram and CI analyses were used for evaluating the combination effect of yanhusuo and ezhu. Cancer cells were treated with serial dilutions of each drug sequentially or both drugs simultaneously at a series of fixed ratio of doses to determine the cell viability. Our results indicated that yanhusuo and ezhu have strong synergistic antitumor effects in MDA-MB-231 cancer cells. We further examined by cell invasion assay, cell cycle distribution and the expression level of several related proteins, and demonstrated that the combination of yanhushuo and ezhu markedly decreased cancer cell proliferation, without significantly affecting cell cycle distribution.

\section{Materials and methods}

Materials. RPMI (Roswell Park Memorial Institute)-1640, fetal bovine serum (FBS), phosphate-buffered saline (PBS), penicillin-streptomycin (PS) and $0.25 \%(\mathrm{w} / \mathrm{v})$ trypsin/ $1 \mathrm{mM}$ EDTA were purchased from Invitrogen (Carlsbad, CA, USA). DMSO (dimethyl sulfoxide) was supplied by Sigma (St. Louis, MO). Matrigel ${ }^{\text {TM }}$ basement membrane matrix was purchased from BD Biosciences (Bedford, MA). Antibodies against ERK 1/2, phospho-ERK 1/2, phospho-Rb (S795) and phospho-Rb (Ser807/811) were obtained from Cell Signaling (Danvers, MA, USA).

Preparation of extracts and quality analysis. Two different sets of the rhizome of Corydalis yanhusuo W.T. Wang and Curcuma wenyujin Y.H. Chen et C. Ling ( $7 \mathrm{~g}$ for each sample) were cut into small pieces, ground into a fine powder, and extracted by $95 \%$ alcohol 5 times. After retrieving the alcohol, the extract was frozen dried, resulting in $C$. yanhusuo extract of $1.80 \%(\mathrm{w} / \mathrm{w})$ and $1.68 \%, C$. wenyujin $3.25 \%(\mathrm{w} / \mathrm{w})$ and $2.98 \%$. The main components of the extracts were described in our previous study $(11,14)$. The stock solutions of the extracts for tests $(60 \mathrm{mg} / \mathrm{ml})$ were prepared in DMSO.

HPLC analysis method was necessary for evaluation the quality of extracts which were used in our study. The HPLC detection for yanhusuo was achieved by an Agilent SB C18 column $(250 \mathrm{~mm} \times 4.6 \mathrm{~mm}$, id=5 $\mu \mathrm{m})$ along with a pre-column filled with the same stationary phase. A linear gradient elution of $\mathrm{A}(0.2 \%$ acetic acid solution, adjusted with triethylamine to $\mathrm{pH} 5.0$ ) and $\mathrm{B}$ (acetonitrile) was used according to the following profile: $0-8 \mathrm{~min}, 20 \% \mathrm{~B} ; 8-25 \mathrm{~min}$ linear increase to $80 \% \mathrm{~B} ; 25-30$ min linear decrease to $20 \% \mathrm{~B} ; 30-37 \mathrm{~min}$ $20 \%$ B (15). The extracts were solved with $50 \%$ acetonitrile in $10 \mathrm{mg} / \mathrm{ml}$ and filtered through a $0.45 \mu \mathrm{m}$ membrane filter before delivered into the system. The solvent flow rate was $1.0 \mathrm{ml} / \mathrm{min}$ and the column temperature was set at $25^{\circ} \mathrm{C}$. The injection volume was $10 \mu \mathrm{l}$. The HPLC chromatogram was monitored at $256 \mathrm{~nm}$.

The HPLC detection for ezhu was achieved by an Agilent ODS column ( $250 \mathrm{~mm} \times 4.6 \mathrm{~mm}, \mathrm{id}=5 \mu \mathrm{m})$ along with a precolumn filled with the same stationary phase. A linear gradient elution of A (Milli-Q water) and B (acetonitrile) was used according to the following profile: 0-10 $\mathrm{min}, 20 \% \mathrm{~B}$ linear increase to $40 \%$; $10-15 \mathrm{~min}$ linear increase to $47 \% \mathrm{~B}$; 15-25 min linear increase to $65 \% \mathrm{~B} ; 25-35 \mathrm{~min}$ linear increase to $90 \% \mathrm{~B} ; 35-50 \mathrm{~min}$ linear increase to $100 \% \mathrm{~B} ; 50-60 \mathrm{~min}$ $100 \% \mathrm{~B}$. The extracts were solved with $50 \%$ acetonitrile in $10 \mathrm{mg} / \mathrm{ml}$ and filtered through a $0.45 \mu \mathrm{m}$ membrane filter before delivered into the system. The solvent flow rate was $1.0 \mathrm{ml} / \mathrm{min}$ and the column temperature was set at $25^{\circ} \mathrm{C}$. The injection volume was $10 \mu$ l. The HPLC chromatogram was monitored at $214 \mathrm{~nm}$ (14).

Cell lines and culture. MDA-MB-231 cells (human breast cancer cell line) were purchased from ATCC (Manassas, VA, USA) and cultured at $37^{\circ} \mathrm{C}$ and $5 \% \mathrm{CO}_{2}$ in RPMI-1640 medium supplemented with $10 \%$ FBS, $100 \mu \mathrm{g} / \mathrm{ml}$ streptomycin and $100 \mathrm{U} / \mathrm{ml}$ penicillin. MDA-MB-231 cells in exponential growth phase were seeded to the plates or dishes. After $24 \mathrm{~h}$, the cells were attached to the bottom of the plate and different concentrations of drug-containing medium were added.

Evaluation of cytotoxicity. The effects of both extracts on cell viability were estimated with the MTT [3-(4, 5-dimethyl-2thiazolyl)-2, 5-diphenyl tetrazolium bromide] assay. The method was previously described (11). Briefly, MDA-MB231 cells were seeded at $2 \times 10^{4}$ cells/well density in 96-well plates. Drug-containing medium $(100 \mu 1)$ were added to treatment for $48 \mathrm{~h}$. Cell inhibition was monitored by the classical MTT assay at $570 \mathrm{~nm}$ using a multilabel counter (Perkin Elmer, 1420 Multilabel Counter Victor ${ }^{3}$, Wellesley, MA, USA). The relative growth rate was defined as the percentage of the absorbance of the treated cells compared to that of the untreated cells. Dose-response curves were generated. The cytotoxicity of the extracts in the ratio of ezhu:yanhusuo (E:Y)=1:18, 1:6, 1:2, 3:2, 9:2, 27:2, 81:2, 243:2 were detected. Subsequently, according to the results from the pilot screening, the cell viability in the ratio of $2: 3$, 3:2, 2:1, 100:1, 250:2 and 150:1 were also detected.

Evaluation of combination effect using the CI method. The effect of the drug combinations was analyzed by the method of Chou and Talalay $(16,17)$, which is one of the most commonly-used methods to evaluate the combination effect by median effect analysis. In brief, the two drugs were administered at a fixed ratio, the dose of the combination required to produce fractional survival $\mathrm{f}$ could be divided into the com-ponent doses (D) $)_{1}$ and $(\mathrm{D})_{2}$ of ezhu and yanhusuo, respectively. For each level of cytotoxicity, the CI was then calculated according to following equation:

$$
\mathrm{CI}=(\mathrm{D})_{1} /(\mathrm{Df})_{1}+(\mathrm{D})_{2} /(\mathrm{Df})_{2}+\alpha(\mathrm{D})_{1}(\mathrm{D})_{2} /(\mathrm{Df})_{1}(\mathrm{Df})_{2}
$$

where (D) $)_{1}$ and (D) $)_{2}$ are the concentrations of the combination required to produce survival $\mathrm{f},(\mathrm{Df})_{1}$ and $(\mathrm{Df})_{2}$ are the concentrations of the individual drugs required to produce $\mathrm{f}$. The CIs were calculated based on the most conservative assumption of drug interactions as followed: if the effect of two agents is 'mutually exclusive' (similar mode of action), than $\alpha=0$, otherwise, $\alpha=1$ (non-exclusive, differ in their action). In this method, the CI indicates antagonism $(\mathrm{CI}>1)$, additivity $(\mathrm{CI}=1)$, or synergism $(\mathrm{CI}<1)$. The linear correlation coefficient $\mathrm{r}$ 
was generated for each curve to determine the applicability of the data to this method of analysis. In all experiments, $\mathrm{R}^{2}>0.9$.

Evaluation of the combination effect using isobologram method. Isobologram is another mathematical approach which has been used to determine the level of drug interaction (18-20). Cell viability results were analyzed by plotting an 'envelope of additivity' on the isobologram. Three curves, referred to as Mode 1, Mode 2a and Mode 2b, were obtained by measuring the mean dose-response curves for two agents given alone. If data points for combinations fall to the left of the envelope, synergy is indicated, if the data fall within the line of mode 1 , drug interaction is said to be additive (summation of effects). If the data points fall to the right of the envelope then the combination is considered subadditive (antagonistic).

Cell invasion assay. Cell invasion assay was carried out using a modified Boyden Chamber assay. Briefly, various amounts of Matrigel (40 $\mu \mathrm{g}$ for the upper side and $32 \mu \mathrm{g}$ for the lower side) were coated on the chambers for $6 \mathrm{~h}$ at $37^{\circ} \mathrm{C}$. MDAMB-231 cells were suspended in serum-free RPMI-1640 $\left(2.5 \times 10^{5}\right.$ cells $\left./ \mathrm{ml}\right)$. RPMI-1640 medium $(500 \mu \mathrm{l})$ (containing $1 \%$ FBS and various concentrations of YHS extracts) was added to the lower chamber, and a $200 \mu 1$ cell suspension (containing corresponding concentrations of extracts) was added to the upper chamber. The transwell plate was incubated for $12 \mathrm{~h}$ at $37^{\circ} \mathrm{C}$ in the presence of $5 \% \mathrm{CO}_{2}$. Non-migrating cells were carefully removed from the upper surface of the insert with a cotton swab. The migrated cells were fixed overnight in $3.7 \%$ formaldehyde at $4^{\circ} \mathrm{C}$ and stained with Hoechst 33258 in PBS (1:1000) for $15 \mathrm{~min}$. The filters were then rinsed thoroughly in PBS and mounted on glass slides. To quantify cell motility, cells that had migrated to the bottom surface of the filter were counted. Three evenly-spaced fields of cells were collected for each well at x100 magnification using an Axiovert 200 fluorescent inverted microscope (Carl Zeiss, HK) and an AxioCam HRC CCD camera (Carl Zeiss). The images were counted with Metamorph imaging series software (Molecular Devices, Tokyo, Japan). All assays were performed in triplicate.

Cell cycle analysis. Cell pellet was fixed with $1 \mathrm{ml}$ of cold $70 \% \mathrm{EtOH}$ at $4^{\circ} \mathrm{C}$ for $12 \mathrm{~h}$. After removing the ethanol, $1 \mathrm{ml}$ of propidium iodide (PI) stain solution $(20 \mu \mathrm{g} / \mathrm{ml}$ of PI and $5 \mu \mathrm{g} / \mathrm{ml}$ of DNase-free RNase) was added to the sample. Then cells $(30,000)$ were analyzed on a flow cytometry (BD FACS Canto ${ }^{\mathrm{TM}}$, Franklin Lakes, NJ). The red fluorescence (PE) representing the DNA content (propidium iodide) was collected through a 585-nm filter. Data were analyzed using Mod Fit LT 3.0 software.

Apoptosis analysis. Cytochrome c release was assessed by a SelectFX Alexa Fluor 488 cytochrome c apoptosis detection kit (molecular probes) (21). Cells were seeded in 24-well plates and treated with various concentrations of herbal extract for $24 \mathrm{~h}$. The media were discarded and the cells were washed with warm PBS, fixed with fresh $4 \%$ formaldehyde in PBS for 15 min at $37^{\circ} \mathrm{C}$, and permeabilized with $0.2 \%$ Triton $\mathrm{X}-100$ for $5 \mathrm{~min}$ at room temperature. The cells were washed and incubated in a blocking buffer (10\% heat-inactivated normal goat serum) for $30 \mathrm{~min}$ at room temperature. The cells were then incubated with 500-fold dilution of the anti-cytochrome $\mathrm{c}$ antibody at room temperature for $4 \mathrm{~h}$, and than incubated with a 1,000-fold dilution of the Alexa Fluor ${ }^{\circledR}$ 488-labeled secondary antibody for $1 \mathrm{~h}$. Finally, $0.5 \mathrm{ml}$ of the propidium iodide $(1: 1000$ in PBS $) /$ RNase A $(5 \mu \mathrm{g} / \mathrm{ml})$ staining buffer were added to each sample. The cells were incubated and protected from light for an additional $30 \mathrm{~min}$ at room temperature. Green fluorescence was observed with a fluorescent microscope.

Western blotting. SDS-PAGE and Western blotting were performed to evaluate the protein levels of ERK1/2 and phospho-ERK1/2. Briefly, cells were treated as designated in $1 \%$ FBS RPMI-1640 for $2 \mathrm{~h}$. Cell pellets were lysed in RIPA lysis buffer (Santa Cruz, CA) with 1\% PMSF and 1\% phosphatase inhibitor cocktail. After treatment on ice for $30 \mathrm{~min}$, cell lysates were clarified by centrifugation at 11,419 $\mathrm{x}$ g for $20 \mathrm{~min}$ at $4^{\circ} \mathrm{C}$ to remove cell debris, and the protein content was measured using a BCA protein assay kit (Pierce, Rockford, IL). Total protein $(40 \mu \mathrm{g})$ were subjected to $10 \%$ SDS-PAGE (with 6\% stacking gel) and transferred to a PVDF membrane (Bio-Rad, Hercules, CA). The membrane was probed with primary antibody [1:2000 for ERK 1/2, 1:1000 for phosphoERK 1/2, phospho-Rb (S795) and phospho-Rb (Ser807/811)] followed by second antibody and visualized using an ECL advanced Western blotting detection kit (Amersham, UK) according to the manufacturer's protocol. Densitometric measurements of band intensity in the Western blots were performed using Quantity One software (Bio-Rad).

Statistical analysis. Unless otherwise indicated, experiments were repeated and three replicates yielded coefficients $R$ $>0.9$ for all three median effect lines. Results of multiple experiments are presented as mean of the indicated level of growth inhibition. Significance was determined using Oneway ANOVA followed by the Games-Howell method, and accepted at $\mathrm{p}<0.05$.

\section{Results}

The HPLC analysis of yanhusuo and ezhu extracts. The typical chromatograms of the yanhusuo and ezhu extracts are shown in Fig. 1. The identification of the peaks was performed by comparing their retention time and UV character of the peaks with the standards or references. The chromatography (HPLC; Fig. 1A for yanhusuo and Fig. 1B for ezhu) showed that the components and their contents from two different sets of yanhusuo and ezhu extracts were similar.

Moreover, we deteminated the contents of the dehydrocorydaline, berberine, and palmatine, the contents of these compounds in yanhusuo extracts were, respectively, $2.925 \%$, $0.75 \%$, and $0.275 \%$. Stock solutions of the YHS extract of $100,30,10$, and $3 \mathrm{mg} / \mathrm{ml}$ were prepared in DMSO.

Cytotoxicity of single extract in MDA-MB-231 cells. We tested the cytotoxicity of individual extract in breast cancer line MDA-MB-231 cells. As shown in Fig. 2A, either YHS 


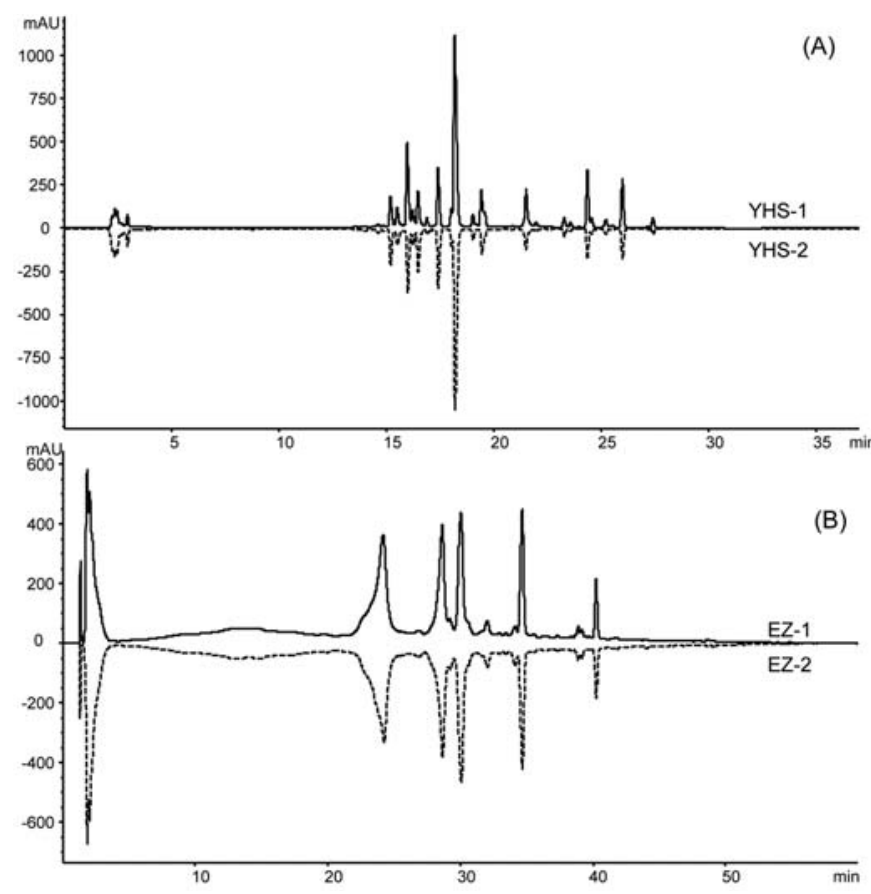

Figure 1. HPLC chromatograms of the ethanol extracts of yanhusuo and ezhu. (A) HPLC-DAD chromatograms of two different sets of yanhusuo extract. (B) HPLC-DAD chromatograms of two different sets of ezhu extracts.

Table I. Inhibitory concentration of each drug at $48 \mathrm{~h}(\mu \mathrm{g} / \mathrm{ml})$.

\begin{tabular}{lrrrrr}
\hline & $\mathrm{IC}_{10}$ & $\mathrm{IC}_{20}$ & $\mathrm{IC}_{30}$ & $\mathrm{IC}_{40}$ & $\mathrm{IC}_{50}$ \\
\hline Ezhu extract & 80.49 & 97.42 & 111.79 & 125.74 & 140.34 \\
Yanhusuo extract & 80.26 & 114.11 & 147.07 & 182.68 & 223.71 \\
\hline
\end{tabular}

extract or ezhu extract exhibited a significant growth inhibitory effect on MDA-MB-231 cells after $48 \mathrm{~h}$ treatment. The cell proliferation of MDA-MB-231 cell was suppressed by either extract in a dose-dependent manner. Furthermore, the probit analysis of SPSS software (SPSS 13.0 for Windows) was used to calculate the inhibitory concentrations of both ezhu and yanhusuo (Table I). The $\mathrm{IC}_{50}$ for ezhu and yanhusuo extracts were $\sim 140 \mu \mathrm{g} / \mathrm{ml}\left[(\mathrm{Df})_{1}\right]$ and $224 \mu \mathrm{g} / \mathrm{ml}\left[(\mathrm{Df})_{2}\right]$, respectively.

Combination of yanhusuo and ezhu on inhibition MDA-MB231 cell proliferation

CI method. The CI-value of $\mathrm{E}: \mathrm{Y}=1: 18,1: 6,1: 2,3: 2,9: 2$, $27: 2,81: 2,243: 2$ were detected, and the result showed that the CI-value in the ratio of 3:2 (A:B) exposed the strongest synergistic effect (data not shown). Therefore, a further evaluation of the synergistic effect in $2: 3,3: 2,2: 1,100: 1$, 250:2 and 150:1 (A:B, E:Y) was carried out and the CI-values are shown in Table II. As a result, the CI-value of E3Y2 was the lowest, only 0.5833 .

Isobologram method. We used the classical isbologram to evaluate the drug-drug interacting between ezhu and yanhusuo extracts $(22,23)$. As a result, the data points of E3Y2 at the left of the line (data not shown) indicated that the
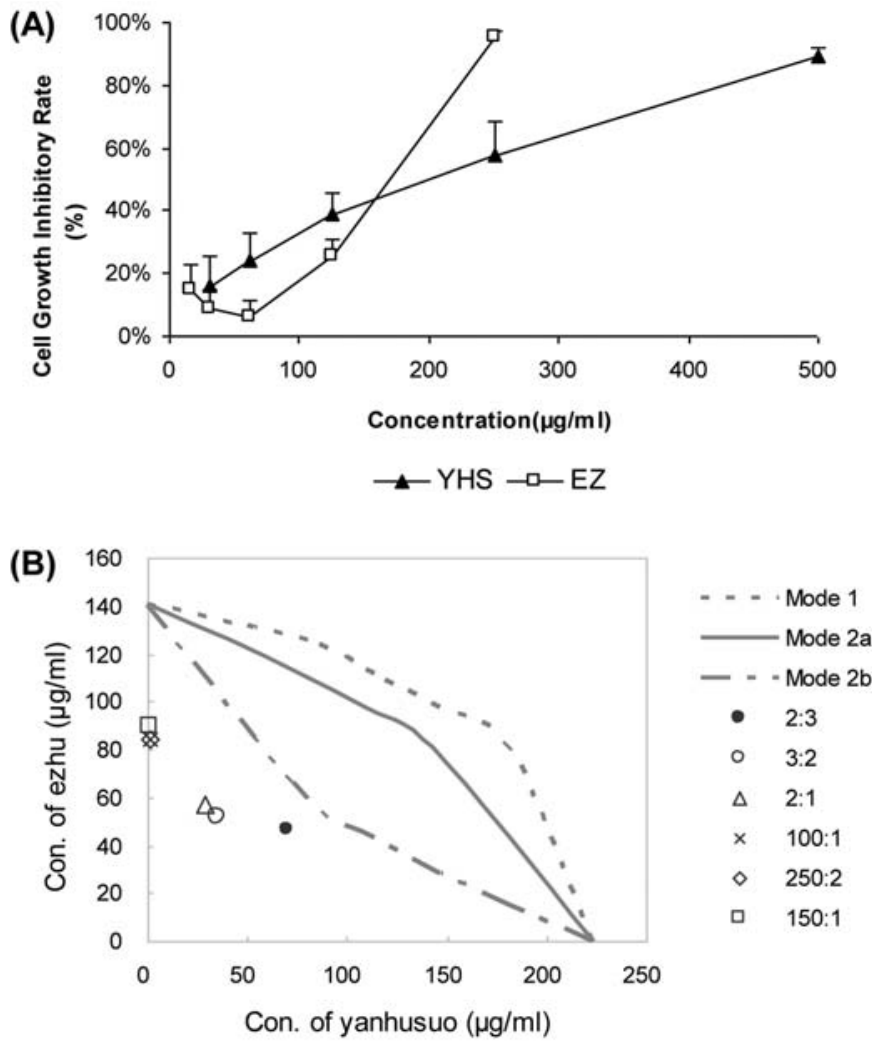

Figure 2. Isobolograms evaluating the synergy between ezhu and yanhusuo. (A) Effects of yanhusuo and ezhu extracts on the proliferation of MDA-MB231 cells $(n=24)$. (B) The isobologram of ezhu and yanhusuo. The mode lines were drawn based on the method described in Materials and methods, and the points plotted on the isobolograms were based on the results of cytotoxicity assays from Table I.

Table II. CI-values of different ratios.

\begin{tabular}{lccccc}
\hline Ratio & $\begin{array}{c}(\mathrm{D})_{1} \\
(\mu \mathrm{g} / \mathrm{ml})\end{array}$ & $\begin{array}{c}(\mathrm{D})_{2} \\
(\mu \mathrm{g} / \mathrm{ml})\end{array}$ & $\begin{array}{c}\text { Regression } \\
\text { equation }\end{array}$ & $\mathrm{R}^{2}$ & $\mathrm{CI}$ \\
\hline $2: 3$ & 46.27 & 69.40 & $\mathrm{Y}=1.681-0.308 \mathrm{LnX}$ & 0.979 & 0.7422 \\
$3: 2$ & 52.03 & 34.69 & $\mathrm{Y}=1.729-0.311 \mathrm{LnX}$ & 0.930 & 0.5833 \\
$2: 1$ & 57.58 & 28.79 & $\mathrm{Y}=1.874-0.339 \mathrm{LnX}$ & 0.904 & 0.5917 \\
$100: 1$ & 84.21 & 0.84 & $\mathrm{Y}=2.792-0.517 \mathrm{LnX}$ & 0.941 & 0.6061 \\
$250: 2$ & 84.19 & 0.67 & $\mathrm{Y}=2.721-0.501 \mathrm{LnX}$ & 0.932 & 0.6047 \\
$150: 1$ & 89.77 & 0.60 & $\mathrm{Y}=2.987-0.553 \mathrm{LnX}$ & 0.929 & 0.6441 \\
\hline
\end{tabular}

(D) $)_{1}$ and $(\mathrm{D})_{2}$ are the concentrations of the combination required to produce $50 \%$ survival.

combined effects of E3Y2 have the strongest synergistic effect. Furthermore, a modified isobolographic analysis revealed significant synergy in several ratios between ezhu extract and yanhusuo extracts, such as at the ratio of 2:1 and 3:2 (Fig. 2B). The data points are out of the area of envelope and fall to the left of the envelope, so the combinations are considered synergy or supra-additivity.

Effects of yanhusuo and ezhu extracts on cell invasion. Results from combination analysis of yanhusuo and ezhu extracts indicated that ezhu and yanhusuo extracts have a significant synergy in the ratio of 3:2 (E3Y2). Therefore, we tested the 

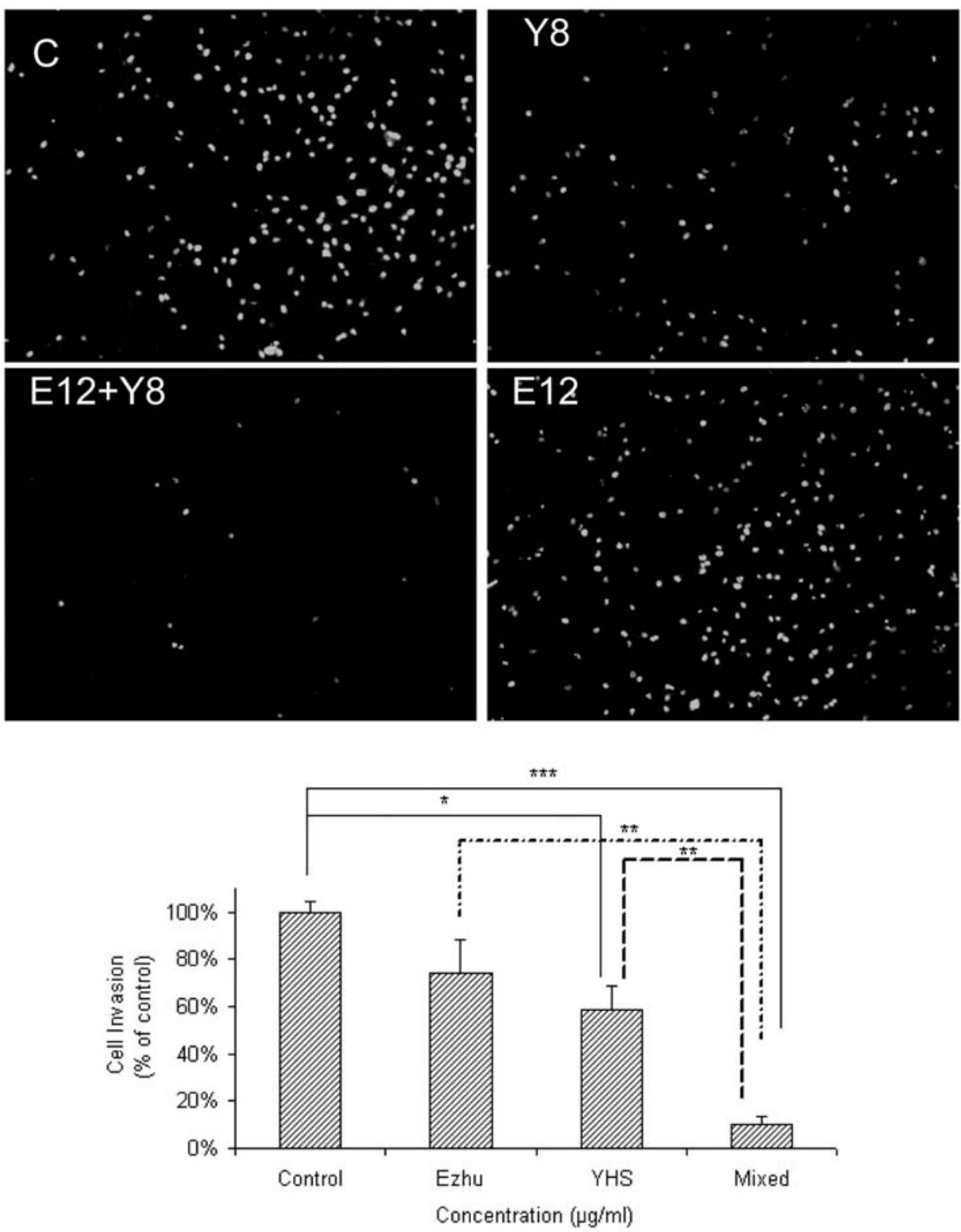

Figure 3. Effect of ezhu, yanhusuo and mixed extract on the invasion of MDA-MB-231 cells (x50). MDA-MB-231 cells were fixed after $12 \mathrm{~h}$ of treatment with described concentration of drugs. The data represent were from 3 separate experiments $(n=9) .{ }^{* * *} \mathrm{p}<0.001,{ }^{* *} \mathrm{p}<0.01,{ }^{*} \mathrm{p}<0.05$ vs. vehicle control group.

cell invasive ability of the cells treated with the mixed extracts $\mathrm{E}: \mathrm{Y}=12: 8 \mu \mathrm{g} / \mathrm{ml}$. The mixed extracts led to a significant inhibition of MDA-MB-231 cell invasion on Matrigel (Fig. 3). The ability of cells to invade was reduced, respectively, to $74.5,58.5$, and $10.0 \%$ after treatment with ezhu $(12 \mu \mathrm{g} / \mathrm{ml})$, yanhusuo $(8 \mu \mathrm{g} / \mathrm{ml})$ and mixed extracts E3Y2.

Effects of yanhusuo and ezhu extracts on cell cycle. The effects of ezhu, yanhusuo and mixed extracts on cell cycle progression of MDA-MB-231 cells were studied after $24 \mathrm{~h}$ of drug exposure. The result showed that $12 \mu \mathrm{g} / \mathrm{ml}$ ezhu extract, $8 \mu \mathrm{g} / \mathrm{ml}$ yanhusuo extract, or the mixed extracts did not have any remarkable effect on cell cycle distribution (data not shown).

Effects of yanhusuo and ezhu extracts on cell apoptosis. Cytochrome c released from the mitochondria to the cytosol is implicated in mitochondria-dependent apoptosis. Cytochrome c staining in the cell cytosol of MDA-MB-231 cells showed markedly higher levels of green fluorescence than that of control cells at $24 \mathrm{~h}$ after treatment with $12 \mu \mathrm{g} / \mathrm{ml}$ of ezhu. Moreover, cells treated with the combination with ezhu and yanhusuo extracts showed an apparent increase in punctate green fluorescence staining and decrease in red fluorescence staining (Fig. 4). The results indicated that the combination treatment of ezhu and yanhusuo extract significantly accelerated the release of cytochrome $\mathrm{c}$ and the aggregation of chromatin (Fig. 4).

Effects of yanhusuo and ezhu extracts on phosphorylation of $E R K 1 / 2$ and $R b$. ERK1/2 plays a critical role in regulating cell growth and development (25). To determine the combination effect of ezhu and yanhusuo extracts on ERK activation in MDA-MB-231, cells were cultured in $12 \mu \mathrm{g} / \mathrm{ml}$ ezhu extract, $8 \mu \mathrm{g} / \mathrm{ml}$ yanhusuo extract and mixed extracts for $2 \mathrm{~h}$. Cells treated with mixed extracts exhibited a reduction in the 


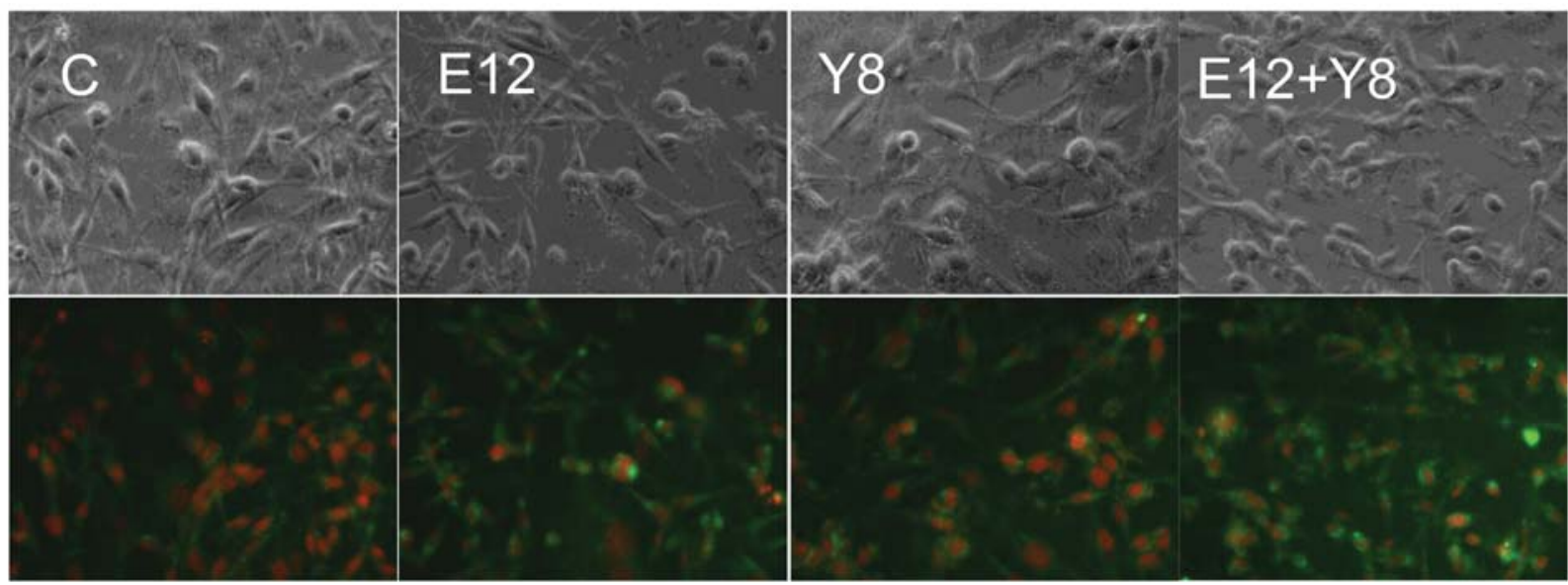

Figure 4. Representative microscopic photographs of cytochrome c immunostaining in MDA-MB-231 cells treated with ezhu, yanhusuo and mixed extract. Cytochrome c immunofluorescence was observed with Oregon Green, and the karyon was observed with red fluorescence. Similar results were obtained from three separate experiments (original magnification, $\mathrm{x} 400$ ).

\section{Control EZ YHS E+Y}

ERK

\section{Phospho-ERK}

Phospho-Rb(S795)

\section{Phospho-Rb (Ser807/811)}

\section{Beta-actin Mouse mAb}

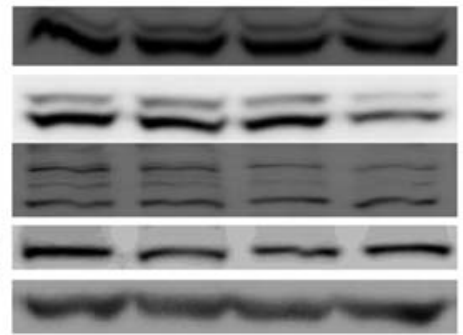

Figure 5. Effects of ezhu, yanhusuo and mixed extract on the expression of ERK1/2, phospho-ERK1/2 and phospho-Rb in MDA-MB-231 cells. Cells were treated with $12 \mu \mathrm{g} / \mathrm{ml}$ ezhu, $8 \mu \mathrm{g} / \mathrm{ml}$ yanhusuo and mixed extract (E:Y=12 $\mu \mathrm{g} / \mathrm{ml}: 8 \mu \mathrm{g} / \mathrm{ml}$ ) for $2 \mathrm{~h}$. Western blot of whole cell lysates was performed as described in Materials and methods.

phosphorylation of ERK 1/2 compared to those treated with ezhu or yanshusuo alone (Fig. 5).

The tumor suppressor protein retinoblastoma $(\mathrm{Rb})$ plays an important role in controlling the progression through the late $\mathrm{G} 1$ restriction point and is a major regulator of the $\mathrm{G} 1 / \mathrm{S}$ transition. We found that the expression levels of phosphorylation $\mathrm{Rb}$ proteins were hardly influenced by the treatment of $12 \mu \mathrm{g} / \mathrm{ml}$ ezhu, $8 \mu \mathrm{g} / \mathrm{ml}$ yanhusuo and mixed extract (Fig. 5). The Western blotting results were consistent with that of the cell cycle analysis, suggesting that the mixed extracts may suppress cell growth by induced cell apoptosis rather than cell cycle arrest.

\section{Discussion}

We previously reported that yanhusuo extract can inhibit breast cancer cell migration and invasion by suppressing the ERK1/2 signalling pathway (11). Ezhu (essential oil of Curcuma wenyujin) exhibits an anti-proliferative effect on HepG2 cells by inducing apoptosis (12). This growth inhibition is associated with cell cycle arrest, cytochrome c translocation, caspase 3 activation, Poly-ADP-ribose polymerase (PARP) degradation, and loss of mitochondrial membrane potential $(12,13)$. These findings strongly suggest that ezhu and yanhusuo may exert their anti-cancer activity through different mechanisms. Thus, it is conceivable that a combination therapy using both ezhu and yanhusuo extracts may achieve a synergistic effect.

In this study, we evaluated the drug-drug interaction between ezhu extract and yanhusuo extracts using the CI method and isobologram methodology. The foundation of both $\mathrm{CI}$ and isobologram was $\mathrm{E}=\mathrm{D} /\left(\mathrm{D}_{50}+\mathrm{D}\right)$, where $\mathrm{D}$ is the concentration, $\mathrm{D}_{50}$ is the concentration that produce $50 \%$ survival, E is the effect (8). Thus, neither isobologram nor CI analyses provide output of concentration-effect curves for investigator evaluation. However, CI provided an exact value for comparing the synergy levels among different ratios, and isobologram is a qualitative method for judgment of the synergy, additive or antagonistic in the fix ratio. We found that ezhu and yanhusuo extracts exhibited the strongest synergistic effect at the ratio of 3:2 (E3Y2). Nevertheless, our data suggested that not all combination ratios of ezhu and yanhusuo had synergistic effect. The optimal synergy ratio of drug-drug interaction at the ratio of 3:2 was further confirmed by cell invasion assay, cytochrome c release assay and inhibition of phospho-ERK1/2. We found that E3Y2 markedly reduced the cell invasion ability and induced cytochrome $\mathrm{c}$ release rather than single use, but E3Y2 did not influence the cell cycle distribution $(25,26)$.

It has been well established that increasing the intracellular concentrations of anticancer agents and overcoming drug-resistance may be another major cause of synergy for anticancer agents, such as the synergy between anticancer drugs and calcium influx blockers (27). It is well known that inhibition of the MEK-ERK-RSK pathway down-regulates $\mathrm{P}$-gp expression levels and diminishes cellular multidrug resistance $(24,28)$. Our studies demonstrated that ezhu and yanhusuo extracts exert a significant synergistic effect on inhibiting phosphorylation of ERK1/2 protein. Consistent with our findings are several studies in which the active compounds of ezhu and yanhusuo, such as curcumin, curcuminoids, berberine and dl-tetrahydropalmatine (29-32), functioned as effective MDR and/or P-gp modulators. 
In conclusion, we propose that the synergy observed in the cytotoxic effects of ezhu and yanhusuo in the human breast cancer cell line, MDA-MB-231, was caused by suppressing cancer cell proliferation and invasion. The mechanisms should be related with the down-regulation of phosphoERK $1 / 2$ and enhancement of the cytochrome c release. Therefore, future studies should be devoted towards validating the in vitro findings under in vivo conditions. Moreover, it is conceivable that potential synergistic effects between three or more agents/herbal extracts may be conducted using three- or higher-dimensional isobolograms. This may be an important direction for TCM research in order to evaluate the combination effects of more than two compounds in herbal extracts.

\section{Acknowledgements}

This work was supported in part by research grants from the Macao Science and Technology Development Fund (029/ 2007/A2) and the University of Macau (RG075/06-07S/ WYT/ICMS).

\section{References}

1. Baxevanis CN, Perez SA and Papamichail M: Combinatorial treatments including vaccines, chemotherapy and monoclonal antibodies for cancer therapy. Cancer Immunol Immunother 58: 317-324, 2009

2. Chou TC: Theoretical basis, experimental design, and computerized simulation of synergism and antagonism in drug combination studies. Pharmacol Rev 58: 621-681, 2006.

3. Czuczwar SJ, Kaplanski J, Swiderska-Dziewit G, et al: Pharmacodynamic interactions between antiepileptic drugs: preclinical data based on isobolography. Expert Opin Drug Metab Toxicol (In press).

4. Chou TC: Preclinical versus clinical drug combination studies. Leuk Lymphoma 49: 2059-2080, 2008.

5. Jin HJ, Siwak EB, Smith R, et al: Very strong synergy between modified RANTES and gp41 binding peptides leads to potent anti-HIV-1 activity. Antimicrob Agents Chemother (In press).

6. Bell A: Antimalarial drug synergism and antagonism: mechanistic and clinical significance. FEMS Microbiol Lett 253: 171-184, 2005.

7. Uppuluri P, Nett J, Heitman J, et al: Synergistic effect of calcineurin inhibitors and fluconazole against Candida albicans biofilms. Antimicrob Agents Chemother 52: 1127-1132, 2008.

8. Zhao L, Wientjes MG and Au JL-S: Evaluation of combination chemotherapy: integration of nonlinear regression, curve shift, isobologram, and combination index analyses. Clin Cancer Res 10: 7994-8004, 2004.

9. Wagnera $\mathrm{H}$ and Ulrich-Merzenich G: Synergy research: Approaching a new generation of phytopharmaceuticals. Phytomedicine 16: 97-110, 2009.

10. Ung CY, Li H, Cao ZW, et al: Are herb-pairs of traditional Chinese medicine distinguishable from others? Pattern analysis and artificial intelligence classification study of traditionally defined herbal properties. J Ethnopharmacol 111: 371-377, 2007.

11. Gao JL, Shi JM, He K, et al: Yanhusuo extract inhibits metastasis of breast cancer cells by modulating mitogen-activated protein kinase (MAPK) signaling pathways. Oncol Rep 20: 819-824, 2008.

12. Xiao Y, Yang FQ, Li SP, et al: Furanodiene induces G2/M cell cycle arrest and apoptosis through MAPK signaling and mitochondria-caspase pathway in human hepatocellular carcinoma cells. Cancer Biol Ther 6: 1044-1050, 2007.
13. Xiao Y, Yang FQ, Li SP, et al: Essential oil of Curcuma wenyujin induces apoptosis in human hepatoma cells. World J Gastroenterol 14: 4309-4318, 2008.

14. Yang FQ, Wang YT and Li SP: Simultaneous determination of 11 characteristic components in three species of Curcuma rhizomes using pressurized liquid extraction and highperformance liquid chromatography. J Chromatogr A 1134: 226-231, 2006.

15. Ding B, Zhou TT, Fan GR, et al: Qualitative and quantitative determination of ten alkaloids in traditional Chinese medicine Corydalis yanhusuo W.T. Wang by LC-MS/MS and LC-DAD. J Pharm Biomed Anal 45: 219-226, 2007.

16. Chou TC and Talalay P: Quantitative analysis of dose-effect relationships: the combined effects of multiple drugs or enzyme inhibitors. Adv Enzyme Regul 22: 27-55, 1984.

17. Takabatake D, Fujita T, Shien T, et al: Tumor inhibitory effect of gefitinib (ZD1839, Iressa) and taxane combination therapy in EGFR-overexpressing breast cancer cell lines (MCF7/ADR, MDA-MB-231). Int J Cancer 120: 181-188, 2007.

18. Wagenpfeil S, Treiber U and Lehmer A: Statistical analysis of combined dose effects for experiments with two agents. Artif Intell Med 37: 65-71, 2006.

19. Naruse T, Nishida Y and Ishiguro N: Synergistic effects of meloxicam and conventional cytotoxic drugs in human MG-63 osteosarcoma cells. Biomed Pharmacother 61: 338-346, 2007.

20. Steel GG and Peckham MJ: Exploitable mechanisms in combined radiotherapy chemotherapy: the concept of additivity. Int J Oncol Biol Phys Radiat 5: 85-93, 1979.

21. Sa F, Gao JL, Fung KP, et al: Anti-proliferative and pro-apoptotic effect of Smilax glabra Roxb. extract on hepatoma cell lines. Chem Biol Interact 171: 1-14, 2008.

22. Tallarida RJ: Drug synergism: its detection and applications. J Pharmacol Exp Ther 298: 865-872, 2001

23. Yoshizawa J, Takizawa A, Takeuchi O, et al: Experimental study of combination therapy with $\mathrm{S}-1$ against pancreatic cancer. Cancer Chemother Pharmacol (In press).

24. McCubrey JA, Steelman LS, Chappell WH, et al: Roles of the Raf/MEK/ERK pathway in cell growth, malignant transformation and drug resistance. Biochim Biophys Acta 1773: 1263-1284, 2007.

25. Medina V, Edmonds B, Young GP, et al: Induction of caspase-3 protease activity and apoptosis by butyrate and trichostatin A (inhibitors of histone deacetylase): dependence on protein synthesis and synergy with a mitochondrial/cytochrome cdependent pathway. Cancer Res 57: 3697-3707, 1999.

26. Kang MH, Wan Z, Kang YH, et al: Mechanism of synergy of N-(4-hydroxyphenyl) retinamide and ABT-737 in acute lymphoblastic leukemia cell lines: Mcl-1 inactivation. J Natl Cancer Inst 100: 580-595, 2008.

27. Yanovich S and Preston L: Effects of verapamil on daunomycin cellular retention and cytotoxicity in P388 leukemic cells. Cancer Res 44: 1743-1747, 1984.

28. Katayama K, Yoshioka S, Tsukahara S, et al: Inhibition of the mitogen-activated protein kinase pathway results in the downregulation of P-glycoprotein. Mol Cancer Ther 6: 2092-2102, 2007.

29. Chearwae W, Anuchapreeda S, Nandigama K, et al: Biochemical mechanism of modulation of human P-glycoprotein (ABCB1) by curcumin I, II, and III purified from Turmeric powder. Biomed Pharmacother 68: 2043-2052, 2004.

30. Limtrakul P, Anuchapreeda S and Buddhasukh D: Modulation of human multidrug-resistance MDR-1 gene by natural curcuminoids. BMC Cancer 4: 13-18, 2004.

31. Lin HL, Liu TY, Wu CW, et al: Berberine modulates expression of mdr1 gene product and the responses of digestive track cancer cells to Paclitaxel. Br J Cancer 81: 416-422, 1999.

32. He L and Liu GQ: Interaction of multidrug resistance reversal agents with P-glycoprotein ATPase activity on blood-brain barrier. Acta Pharmacol Sin 23: 423-429, 2002. 